\title{
Herniorrafia perineal em cães - revisão de literatura
}

\section{Perineal herniorrhaphy in dogs - literature review}

\section{Resumo}

A hérnia perineal ocorre com maior frequência em cães machos não castrados com idade superior a cinco anos. As técnicas cirúrgicas de reparação do diafragma pélvico são diversas, sendo empregadas de forma isolada ou associadas e incluem técnica de sutura padrão, transposição do músculo obturador interno, transposição do músculo glúteo superficial, transposição do músculo semitendinoso, reparação com uso de implantes sintéticos ou biológicos, colopexia e cistopexia. As complicações pós-operatórias associadas são: lesão do nervo isquiático ou pudendo, incontinência fecal ou urinária, prolapso retal, infecção, deiscência de sutura e recidiva da hérnia. Por ser uma enfermidade que apresenta elevados índices de complicações e recidivas, decidiu-se realizar a presente revisão abordando os aspectos gerais e as principais técnicas de tratamento da referida afecção.

\section{Abstract}

Perineal hernia occurs more frequently in non-castrated male dogs aged over five years. Surgical techniques for pelvic diaphragm repair are varied, and can be employed alone or associated with others and include the standard suture technique, transposition of the internal obturator muscle, transposition of the superficial gluteal muscle, transposition of the semitendinosus muscle, repair with synthetic or biological implants, colopexy, and cistopexia. Associated postoperative complications are injury of the sciatic or pudendal nerve, fecal or urinary incontinence, rectal prolapse, infection, wound dehiscence, and hernia recurrence. Since it is a disease with high rates of complications and recurrences, we decided to conduct this review covering general aspects and the main treatment techniques of the disorder. 
Thais Cristine Alves de Assumpção ${ }^{1}$

Julia Maria Matera²

Angelo João Stopiglia ${ }^{2}$
Rua Willis Roberto Banks, 794 - São Domingos

São Paulo, SP, Brasil, CEP: 05128-000

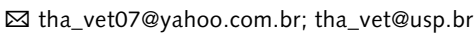

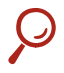

Palavras-chave

Diafragma pélvico.

Complicações. Recidiva.

\section{Keywords}

Pelvic diaphragm.

Complications. Recurrence.
A

hérnia perineal é definida por deslocamento caudal de órgãos abdominais e pélvicos para a região do períneo devido ao enfraquecimento e separação dos músculos e fáscias que formam o diafragma pélvico, podendo ocorrer de forma unilateral ou bilateral (DIETERICH, 1975; HOSGOOD et al., 1995; RAISER, 1994).

Ocorre com maior frequência em cães machos, principalmente não castrados e com faixa etária entre cinco e 14 anos, sendo que vários fatores têm sido associados com a etiologia dessa afecção, tais como predisposição genética, atrofia muscular neurogênica, alterações hormonais, alterações prostáticas e constipação crônica, ocorrendo isoladamente ou associados (DÓREA; SELMI; DALECK, 2002; FERREIRA; DELGADO, 2003; MANN et al., 1995; MERCHAV et al., 2005; VNUK et al., 2006). As raças mais acometidas são: Collies, Boxers, Boston Terrier, Poodle, Pequinês, Dachshunds, Pastor Alemão, assim como cães sem raça definida (RADLINSKY, 2013; ROBERTSON, 1984).

De acordo com a sua localização, a hérnia perineal pode ser classificada em hérnia caudal quando ocorre entre os músculos elevador do ânus, obturador interno e esfíncter anal externo, sendo o tipo mais comum; dorsal quando está localizada entre os músculos elevador 
do ânus e coccígeo; ventral quando ocorre entre os músculos ísquio-uretral, bulbocavernoso e isquiocavernoso; ou ciática quando está localizada entre o ligamento sacrotuberoso e o músculo coccígeo (DORN; CARTEE; RICHARDSON, 1982).

Considerando tratar-se de uma enfermidade que apresenta altas taxas de complicações pós-operatórias e recidivas muito variáveis, objetivou-se com a presente revisão abordar os aspectos gerais e as principais técnicas de tratamento para a correção dessa afecção.

\section{Diagnóstico}

O diagnóstico da hérnia perineal é baseado na anamnese, sinais clínicos, exame físico, radiográficos e ultrassonográficos. Os sinais clínicos mais comuns são tenesmo, constipação crônica, obstipação, disquesia e aumento de volume perineal podendo ou não ser redutível; ver nos casos em que há retroflexão da vesícula urinária, observa-se disúria, oligúria e estrangúria, sendo considerada uma emergência clínica. A palpação retal consiste em um dos exames mais importantes, pois permite determinar as estruturas que compõem a hérnia e avaliar se há a presença de alterações retais, assim como se há aumento do volume prostático (BELLENGER; CANFIELD, 2003; DÓREA; SELMI; DALECK, 2002; FERREIRA; DELGADO, 2003; HOSGOOD et al., 1995; MORTARI; RAHAL, 2005).

Por meio de radiografias simples é avaliada a posição da vesícula urinária e próstata, já o enema baritado possibilita a identificação e diferenciação das alterações retais, e a uretrocistografia confirma se há ou não a ocorrência de retroflexão vesical; por outro lado, a ultrassonografia é efetiva na determinação dos conteúdos herniários. O saco herniário pode ser composto por tecido adiposo retroperitoneal, apresentando na maioria das vezes pequenos nódulos firmes e áreas de necrose, fluido seroso, reto, próstata, vesícula urinária e intestino delgado (BELLENGER; CANFIELD, 2003; KRAHWINKEL, 1983).

O diagnóstico diferencial da hérnia perineal deve ser realizado com: neoplasia perineal, hiperplasia de glândulas perineais, inflamação ou neoplasia dos sacos anais (RADLINSKY, 2013).

\section{Tratamento}

A terapêutica clínica conservativa da hérnia perineal tem como objetivo aliviar e prevenir a obstipação e a disúria, sendo que laxantes, emolientes fecais, dieta com alto teor de fibras e enemas periódicos podem ser utilizados para facilitar a defecação e evitar o acúmulo de fezes no saco herniário. Porém, trata-se de uma medida ineficaz para o controle dos sinais clínicos a longo prazo, e a cirurgia é o tratamento de escolha. Quando retrofletida, a vesícula urinária pode ser descomprimida por cistocentese ou até mesmo por sondagem uretral (ARONSON, 2012; RADLINSKY, 2013).

Diferentes técnicas cirúrgicas individuais ou associadas têm sido relatadas para correção da hérnia perineal em cães, e a maioria preconiza uma abordagem cirúrgica via região perineal para redução do conteúdo herniário e reparação do diafragma pélvico (D’ASSIS et al., 2010). Entre os tratamentos cirúrgicos mais frequentemente utilizados para a reparação do diafragma pélvico estão a técnica de sutura padrão (BELLENGER, 1980; BURROWS; HARVEY, 1973; PETTIT, 1962), transposição do músculo obturador interno (EARLEY; KOLATA, 1983; ORSHER; JOHNSTON, 1985), transposição do músculo glúteo superficial (SPREULL; FRANKLAND, 1980; WEAVER; OMAMEGBE, 1981), transposição do músculo semitendinoso (BARBOSA et al., 2015; CHAMBERS; RAWLINGS, 1991; MORELLO et al., 2015; MORTARI et al., 2005), reparação com uso de implantes sintéticos (CLARKE, 1989; MATERA et al., 1981; SZABO; WILKENS; RADASCH, 2007) ou biológicos (DALECK et al., 1992; DÓREA; SELMI; DALECK, 2002; ZERWES et al., 2011), e colopexia e cistopexia (BARREAU, 2008; BILBREY; SMEAK; DEHOFF, 1990; BRISSOT; DUPRE; BOUVY, 2004).

Independentemente da técnica utilizada para o tratamento da hérnia perineal, recomenda-se a realização de orquiectomia, que determina a redução do nível de testosterona circulante e o volume prostático, pois os cães não castrados apresentam uma taxa de recidiva 2,7 vezes superior à dos cães orquiectomizados (HAYES JUNIOR; WILSON; TARONE, 1978), embora a sua realização como medida de prevenção ou de tratamento adjuvante evitando a recidiva seja contestada por alguns autores (BURROWS; HARVEY, 1973; HARVEY, 1977). Ainda é recomendada a correção de alterações retais concomitantes, pois, a despeito de não se saber se tais alterações estão relacionadas com a causa ou se são consequência da hérnia, alguns autores sugerem que a não correção de defeitos como divertículo, saculação ou dilatação retal contribuem para a recidiva da hérnia (HOSGOOD et al., 1995; KRAHWINKEL, 1983; PEKCAN et al., 2010).

Para a realização do procedimento cirúrgico destinado ao tratamento da hérnia perineal, é necessária uma avaliação hematológica, bioquímica e urinálise, sendo que o protocolo anestésico escolhido é baseado no estado do paciente. Após anestesia, todo material fecal remanescente é manualmente removido do reto. Para a maioria das técnicas de herniorrafia perineal, o animal é posicionado em decúbito ventral, a pelve é elevada e os membros 
pélvicos ficam pendentes sobre a extremidade da mesa cirúrgica, sendo acolchoados na região de contato com a mesa para evitar lesionar o nervo. A cauda é fixada sobre o dorso do animal, insere-se uma gaze no interior do reto e posteriormente efetua-se uma sutura em bolsa de fumo temporária no ânus (ARONSON, 2012; RADLINSKY, 2013).

\section{Técnica Padrão}

Um dos primeiros relatos que descreveram o tratamento cirúrgico da hérnia perineal propôs um método de reparação primário da musculatura do diafragma pélvico por meio da sutura dos músculos esfíncter anal externo, coccígeo e/ou elevador do ânus e obturador interno (PETTIT, 1962). Desde então vários relatos de herniorrafia perineal padrão foram descritos (BELLENGER, 1980; BURROWS; HARVEY, 1973; HARVEY, 1977; HOLMES, 1964; HOSGOOD et al., 1995; RAISER, 1994; SPICCIATI, 1971). Apesar da simplicidade de execução, essa técnica apresenta altas taxas de complicações, tais como tenesmo, incontinência fecal (BURROWS; HARVEY, 1973), prolapso retal (HOSGOOD et al., 1995) e taxas de recidivas variando entre zero (HOLMES, 1964; SPICCIATI, 1971) e 46\% (BURROWS; HARVEY, 1973).

A técnica implica na realização de uma incisão curvilínea iniciando-se cranial ao músculo coccígeo e estendendo-se ventralmente ao assoalho pélvico, sobre a região mais proeminente da hérnia. Em casos de acometimento bilateral, para a correção simultânea de ambos os lados, as incisões podem ser realizadas dos dois lados e ampliadas para o aspecto ventral. Posteriormente são incisados o tecido subcutâneo e o saco herniário. É efetuada a redução das possíveis vísceras pélvicas e/ou abdominais herniadas, as quais são mantidas no interior da cavidade com a introdução de uma compressa úmida. A hérnia é reparada pela passagem de fios de sutura entre o esfíncter anal externo e os músculos coccígeo e/ou elevador do ânus. O ligamento sacrotuberoso pode ser incorporado à sutura para uma reparação mais segura e resistente, com cuidado para evitar o encarceramento do nervo isquiático. Ventralmente, os fios de sutura são passados entre o esfíncter anal externo e o músculo obturador interno com cuidado para não danificar os vasos e nervos pudendos. As suturas são cerradas iniciando-se dorsalmente e progredindo até a região ventral; durante esse procedimento, retira-se a compressa colocada anteriormente na cavidade. Um segundo plano de sutura pode ser realizado unindo a fáscia perineal à margem posterior do esfíncter anal externo. Realiza-se a sutura do tecido subcutâneo e subsequentemente da pele (BURROWS; HARVEY, 1973; PETTIT, 1962; RADLINSKY, 2013; ROBERTSON, 1984).

\section{Transposição do músculo obturador interno}

A técnica de transposição do músculo obturador foi descrita como alternativa à técnica de sutura padrão com intuito de conferir maior reforço à porção ventral da hérnia e menor tensão, além de diminuir as taxas de recidivas (EARLEY; KOLATA, 1983; HARDIE; KOLATA; EARLEY, 1983; ORSHER; JOHNSTON, 1985). As complicações associadas à técnica são tenesmo, disquesia (ZERWES et al., 2011) e incontinência fecal (ACAUI et al., 2010) e as taxas de recidivas variam entre zero (DÓREA; SELMI; DALECK, 2002; HOSGOOD et al., 1995) e 40\% (ZERWES et al., 2011).

Para a realização do procedimento, o acesso é realizado conforme descrito na técnica padrão. Após redução do conteúdo herniário à cavidade e identificação das estruturas, realiza-se uma incisão na borda caudal de origem do músculo obturador interno, que é elevado da superfície isquiática utilizando-se um elevador de periósteo. A elevação do músculo não pode prosseguir além da borda do forame do obturador para evitar lesionar os vasos e nervos correspondentes. O tendão do músculo é incisado em sua porção condensada, onde se inicia sua passagem lateral ao longo do corpo do ísquio, com cuidado para não lesionar o nervo isquiático. $\mathrm{O}$ músculo é elevado dorsalmente e transposto sobre a hérnia. A sutura inicial é realizada entre o músculo esfíncter anal externo, ligamento sacrotuberoso e a fáscia glútea, o mais dorsalmente possível para se obter uma superfície a qual será suturada ao ápice do músculo obturador interno. A borda caudolateral do retalho muscular é suturada ao ápice caudomedial do ligamento sacrotuberoso, com cuidado para não lesionar a artéria glútea caudal e o nervo isquiático. A borda caudomedial do retalho muscular é suturada ao músculo esfíncter anal externo. Todos os fios de sutura são posicionados conforme descrito e posteriormente cerrados, pois dessa maneira eles são adequadamente introduzidos. Em seguida, realiza-se a sutura do subcutâneo e da pele (EARLEY; KOLATA, 1983). Alternativamente, Orsher e Johnston (1985) propuseram a realização da técnica efetuando-se a elevação do músculo obturador interno, sem incisar o tendão e realizando posteriormente a sutura dos músculos coccígeo e elevador do ânus à porção dorsal do músculo esfíncter anal externo. O músculo obturador interno elevado é suturado à porção ventral do músculo esfíncter anal externo e também ao músculo 
coccígeo. Nessa técnica também todos os pontos são inseridos antes das suturas serem atadas. Os autores ainda recomendaram um segundo plano de sutura entre as fáscias perineal, subcutânea e o ápice do músculo esfíncter anal externo.

Acaui et al. (2010) propuseram um método de reparação efetuando a técnica de transposição do músculo obturador interno, mas realizando o acesso dorsal ao ânus e permitindo, assim, a correção bilateral das hérnias, com boa visibilização das estruturas que compõem as fossas isquiorretais. Contudo, ainda há controversa no que se refere à realização do procedimento em tempo único ou em duas etapas, com intervalo de quatro a seis semanas, em razão de o tenesmo e o desconforto pós-operatório serem maiores do que quando é efetuada a herniorrafia unilateral (ACAUI et al., 2010).

\section{Transposição do músculo glúteo superficial}

A técnica de transposição do músculo glúteo superficial foi descrita por Spreull e Frankland (1980). A vantagem dessa técnica em relação ao procedimento padrão é prover maior suporte nos casos em que há atrofia do músculo coccígeo. Como principal complicação, Weaver e Omamegbe (1981) descreveram a deiscência de sutura, já a taxa de recidiva foi de 14\%. Raffan (1993) descreveu o uso da técnica associada à transposição do músculo obturador interno e obteve como resultado $11 \%$ de recidivas.

Para a realização da técnica, o animal é posicionado em decúbito lateral, contrário ao lado acometido. A incisão é efetuada acima do trocânter do fêmur maior de forma curvilínea até o esfíncter anal. A pele e a fáscia do músculo glúteo superficial são rebatidas, o tecido ao redor da fossa isquiorretal é dissecado e o conteúdo herniário é reposicionado de volta à cavidade. Posteriormente, é realizada a dissecção da borda cranial do referido músculo e sua inserção no terceiro trocânter é transeccionada. O músculo glúteo superficial ainda fixo à sua origem no sacro e sua fáscia correspondente são refletidos de forma a recobrir a fossa isquiorretal, preservando-se os vasos e nervos da região. O tendão de inserção do referido músculo é suturado ao esfíncter anal externo caudalmente, assim como o restante ao tecido subjacente dorsal e ventralmente (SPREULL; FRANKLAND, 1980). Alternativamente, o tendão de inserção pode ser suturado ao músculo obturador interno, a borda caudal do retalho muscular suturado ao músculo esfíncter anal externo e a borda cranial ao ligamento sacrotuberoso. Em seguida, realiza-se a sutura do subcutâneo e da pele (WEAVER; OMAMEGBE, 1981).

\section{Transposição do músculo semitendinoso}

A técnica de transposição do músculo semitendinoso foi descrita por Chambers e Rawlings (1991), que relataram a sua utilização em um caso de hérnia perineal ventral recidivante. As complicações associadas são tenesmo (BARBOS et al., 2015) e deiscência de sutura (MORELLO et al., 2015) e as recidivas relatadas variam de ausência de zero (OLIVEIRA et al., 2014) a 73\% (BARBOSA, 2010). Quanto às alterações referentes ao músculo transposto, Mortari et al. (2005) realizaram estudos eletromiográficos, ultrassonografia e análise morfológica constatando que o retalho muscular apresentava algum grau de atrofia, embora a sua capacidade de contração fosse mantida. Com relação às alterações de locomoção, Barbosa et al. (2015), realizando exames baropodométricos antes e após a transposição, concluíram que o procedimento não afeta a função locomotora do membro operado.

A técnica consiste em transpor o músculo do membro contralateral à região mais afetada e é indicada nos casos de hérnia perineal ventral, bilateral ou recidivantes. A incisão é realizada ao longo da borda caudal da tuberosidade isquiática e se estende distalmente ao longo da porção caudal do membro correspondente até a altura do linfonodo poplíteo. $\mathrm{O}$ músculo semitendinoso é dissecado cuidadosamente e a artéria femoral caudal distal é localizada. Na sequência, secciona-se o músculo semitendinoso na altura do linfonodo poplíteo e realiza-se a sutura do coto remanescente. O músculo é rotacionado e a sua extremidade distal é suturada aos músculos coccígeo, obturador interno e fáscia pélvica. A borda medial do músculo é suturada ao aspecto ventral do músculo esfíncter anal externo e a borda caudal é suturada aos músculos ísquio-uretral e bulboesponjoso. Por fim realiza-se a sutura do tecido subcutâneo e pele (CHAMBERS; RAWLINGS, 1991; MORTARI et al., 2005). Outra opção seria refletir o músculo $180^{\circ} \mathrm{e}$ realizar a transposição no lado ipsilateral da hérnia (ARONSON, 2012). Ainda, alternativamente Morello et al. (2015) recomendaram a divisão longitudinal do músculo semitendinoso, poupando as extremidades proximal e distal dos pedículos vasculares e efetuando-se em seguida a dissecção próximo ao linfonodo poplíteo e transposição somente da porção medial do músculo. Barbosa et al. (2015) também propuseram a modificação da técnica, realizando-se a transposição do músculo sem ser incisada a pele na região perineal ventral, onde o tecido subcutâneo foi dissecado formando-se um túnel, destinado à passagem do músculo. 


\section{Membranas}

A utilização de implantes sintéticos ou biológicos na reparação de hérnias perineais é indicada nos casos em que há atrofia da musculatura que compõe o diafragma pélvico e apresenta como desvantagens a possibilidade de rejeição do material e a irritação dos tecidos subjacentes (FERREIRA; DELGADO, 2003; ZERWES et al., 2011).

As membranas biológicas são implantes orgânicos, inertes, constituídos quase que exclusivamente por colágeno, apresentam baixa toxicidade e são resistentes a infecções (CARDOSO et al., 2011). Já no caso dos implantes sintéticos, o material ideal deve ser não alergênico, não carcinogênico e não produtor de reação de corpo estranho, e não devendo ser fisicamente alterado pelos fluidos teciduais. Por outro lado, deve ser: quimicamente inerte, resistente às deformações mecânicas da parede abdominal e passível de esterilização sem sofrer alterações das suas qualidades (LEAL et al., 2012). As taxas de recidiva associadas ao uso de implantes sintéticos variam de zero (MATERA et al., 1981) a 13\% (SZABO; WILKENS; RADASCH, 2007), já as taxas relativas ao uso de membranas biológicas estão distribuídas entre zero (BONGARTZ et al., 2005; ZERWES et al., 2011) e $42 \%$ (FRANKLAND, 1986).

O uso de implantes sintéticos foi inicialmente descrito por Larsen (1966), que utilizou malha plástica inserida no canal herniário e relatou a ausência de complicações. Posteriormente, Clarke (1989) e Matera et al. (1981) descreveram o uso de malha de polipropileno também inserida no canal herniário; a despeito de terem empregado maneiras distintas para a aplicação da malha, os resultados obtidos foram semelhantes. Szabo, Wilkens e Radasch (2007) também utilizaram malha de polipropileno para o reparo da hérnia, mas efetuaram a sua inserção após terem realizado a transposição do músculo obturador interno e relataram $80,5 \%$ de taxa de sucesso.

Stoll et al. (2002), em estudo experimental, empregaram um fragmento de submucosa de intestino delgado de suíno como biomaterial para o reparo de hérnia perineal e relataram a diminuição da taxa de infecção, ausência de seroma e nenhuma evidência de formação excessiva de tecido de granulação. Por outro lado, Frankland (1986) descreveu que em um terço dos casos do reparo da hérnia com o uso de colágeno dérmico de suíno fixado com fio de sutura polidioxanona houve a eliminação de secreção serosanguinolenta pela ferida cirúrgica, concluindo que deveriam ser investigadas modificações na técnica, tais como adequação do fio de sutura para fixação do implante.

Dórea, Selmi e Daleck (2002) compararam a reparação da hérnia pelos métodos de técnica padrão, transposição do músculo obturador e utilização de peritônio bovino conservado em glicerina, e relataram que a técnica de transposição do músculo obturador foi superior às outras por apresentar taxa de recidiva nula. Já Daleck et al. (1992) também utilizaram peritônio bovino para a correção da hérnia e obtiveram resultados satisfatórios com apenas um caso (8\%) de recidiva. Zerwes et al. (2011), por sua vez, utilizaram pericárdio equino conservado em glicerina a 98\% como reforço, após a transposição do músculo obturador interno, e concluíram que a sua utilização diminuiu a ocorrência de deiscência e recidivas.

Pratummintra et al. (2012) descreveram a utilização de fragmento autólogo de túnica vaginal para a correção da hérnia perineal e obtiveram a taxa de sucesso de $90,91 \%$. Os autores relataram ainda que no exame histopatológico da região correspondente foi constatado neovascularização e crescimento de tecido conjuntivo. Bongartz et al. (2005) não tiveram qualquer recidiva quando utilizaram fragmento autógeno de fáscia lata para herniorrafia perineal.

\section{Pexias}

As técnicas de colopexia, cistopexia e deferentopexia são realizadas, na maioria das vezes, associadas a outras técnicas de tratamento e são indicadas principalmente nos casos de retroflexão da vesícula urinária ou de prolapso retal (GRAND; BUREAU; MONNET, 2013).

Quando da realização das técnicas de colopexia, cistopexia ou deferentopexia, é efetuada a herniorrafia e a orquiectomia e, posteriormente, o cólon e a vesícula urinária ou os ductos deferentes são fixados à parede abdominal. Os reposicionamentos vesical e prostático obtidos com a cistopexia ou deferentopexia são indicados para minimizar a pressão sobre o diafragma pélvico e prevenir que tais estruturas se desloquem novamente para a região caudal com redução do risco de recidiva. A fixação do ducto deferente é preferível à cistopexia direta, pois esta apresenta muitas complicações, tais como interferências com a contração normal da vesícula e retenção urinária, possibilidade de lesão da vesícula urinária e suturas inadvertidamente inseridas na mucosa, predispondo a infecções e formação de cálculo urinário. Simultaneamente, a colopexia também é efetiva na redução de anomalias, como saculações, desvios ou divertículos retais, restaurando o formato do cólon e reduzindo o diâmetro retal. Por tratar-se de técnica com resultados positivos e apresentando menor risco de complicações, abordagens abdominais têm sido propostas para a avaliação e reparação dos órgãos envolvidos e correção dos transtornos causados pela inserção de tais órgãos no diafragma pélvico (BARREAU, 2008; BILBREY; SMEAK; DEHOFF, 1990; BRISSOT; DUPRE; BOUVY, 2004). A principal complicação relatada é o tenesmo (BILBREY; SMEAK; DEHOFF, 1990; BRISSOT; DUPRE; BOUVY, 2004; GOBBETTI, 2012) e as taxas de recidiva estão 
situadas entre zero (BARREAU, 2008; BILBREY; SMEAK; DEHOFF, 1990; GOBBETTI, 2012) e 14\% (GRAND; BUREAU; MONNET, 2013).

Para a realização dos procedimentos colopexia e deferentopexia, são efetuadas laparotomia e exposição do cólon e da vesícula urinária. $\mathrm{O}$ cólon é tracionado cranialmente para impedir que se desloque para o espaço perineal e suturado à parede abdominal dorsolateralmente. Os ductos deferentes são tracionados suavemente, deslocando-os das bainhas vaginais para o interior da cavidade abdominal. Institui-se um canal ao nível do músculo transverso do abdômen realizando-se duas incisões paralelas nas fibras musculares e efetuando-se a dissecção romba entre as incisões com pinça hemostática. Em seguida, o ducto deferente do lado correspondente é fixado, retraindo a vesícula urinária e a próstata caudalmente. $\mathrm{O}$ ducto deferente é suturado à parede abdominal e o procedimento é repetido do lado oposto (BILBREY; SMEAK; DEHOFF, 1990; D’ASSIS et al., 2010; FERREIRA; DELGADO, 2003).

\section{Complicações}

As complicações observadas após a reparação de hérnias perineais são diversas e incluem lesão do nervo isquiático, ou nervo pudendo, incontinência fecal, prolapso retal, infecção, deiscência de suturas, necrose da vesícula urinária, incontinência urinária e recidiva da hérnia (MORTARI; RAHAL, 2005).

A lesão do nervo isquiático é uma complicação incomum e pode ocorrer no momento da introdução dos pontos ao redor do ligamento sacrotuberoso. Os sinais clínicos associados são dor acentuada e claudicação temporária à permanente. A neuropraxia temporária também pode ocorrer tanto no nervo ipsilateral como contralateral ao lado acometido, devido ao posicionamento do animal para a realização do procedimento cirúrgico (DIETERICH, 1975; MATTHIESEN, 1989).

Nos casos em que ocorre o prolapso retal, os fatores predisponentes são a introdução de suturas no lúmen retal, esforço excessivo ao defecar, dor, moléstias retais prévias, correção de hérnia bilateral e lesão nervosa ocasionada pela manipulação cirúrgica. A incontinência fecal, que pode ser temporária ou permanente, ocorre por lesão dos nervos pudendo ou retal caudal, ou ainda por lesão do esfíncter anal devido à dissecção ou posicionamento de sutura. Já a necrose da vesícula urinária e a incontinência urinária são incomuns e estão relacionadas à retroflexão da vesícula urinária (MATTHIESEN, 1989).

A infecção, deiscência e/ou formação de abscesso apresentam como fatores predisponentes a contaminação fecal, penetração do lúmen retal no momento da sutura, extensa dissecção, hemorragia e falhas na antissepsia. A bactéria frequentemente isolada é a Escherichia coli, embora ocasionalmente também podem ser isolados microrganismos dos gêneros Proteus, Staphylococcus, Klebsiella ou Pseudomonas. O uso de antibióticos como medida profilática é controverso, assim como a utilização de dreno de Penrose (MATTHIESEN, 1989).

As complicações associadas às recidivas das hérnias perineais são: falha no isolamento das estruturas, sutura realizada de forma inadequada, utilização de materiais inapropriados e tenesmo causado pela presença de divertículos e dilatações retais, e que as taxas de recorrência variam conforme a técnica utilizada para correção da hérnia, experiência do cirurgião, tempo de evolução da afecção, conteúdo herniário e enfermidades associadas (MATTHIESEN, 1989; MORTARI; RAHAL, 2005).

\section{Considerações finais}

Existem diversas técnicas cirúrgicas descritas para a correção da hérnia perineal, e a escolha da técnica a ser empregada varia conforme o tipo, a gravidade da hérnia e a presença de enfermidades concomitantes. As técnicas de transposição muscular parecem ser mais efetivas do que a técnica padrão e a técnica de transposição do músculo semitendinoso tem a vantagem de ser mais bem aplicada nos casos de hérnias ventrais ou recidivantes. $\mathrm{O}$ uso de membranas é indicado, sobretudo nos casos de atrofia muscular dos músculos que compõem o diafragma pélvico. Já as técnicas de pexia podem ser utilizadas associadas com outras técnicas e são indicadas principalmente nos casos de afecções retais concomitantes e retroflexão de vesícula urinária. Porém, as taxas de complicações e recidivas ainda são elevadas. (ㅇ

\section{Referências}

ACAUI, A. et al. Avaliação do tratamento da hérnia perineal bilateral no cão por acesso dorsal ao ânus. Brazilian Journal of Veterinary Research and Animal Science, São Paulo, v. 47, n. 6, p. 439-446, 2010.

ARONSON, L. R. Rectum, Anus, and Perineum. In: TOBIAS K. M.; JOHNSTON S. A. Veterinary Surgery Small Animal. Missouri: Elsevier Saunders, 2012. p. 1564-1601.

BARBOSA, P. M. L. Análise cinética da locomoção aplicada à técnica de transposição do músculo semitendinoso na reparação de hérnia perineal bilateral em cães. 2010. $100 \mathrm{f}$. Tese (Doutorado em Ciências) - Faculdade de Medicina Veterinária e Zootecnia, Universidade de São Paulo, São Paulo, 2010.

BARBOSA, P. M. L. et al. Kinetic Gait Analysis of Dogs Submitted to Bilateral Perineal Hernia Repair Using Semitendinosus Muscle Transposition. Indian Journal of Applied Research, Ahmedabad, India, v. 5, n. 3, p. 544-547, 2015.

BARREAU, P. Perineal hernia: three steps in one surgery: pexy, sterilisation, repair. Proceedings. In: WORLD SMALL ANIMAL VETERINARY ASSOCIATION WORLD CONGRESS, 14., 2008, Dublin. Proceedings... Dublin: World Small Animal Veterinary Association, 2008.

BELLENGER, C. R. Perineal hernia in dogs. Australian Veterinary Journal, New South Wales, v. 56, n. 9 , p. $434-438$, Sept. 1980 
BELLENGER, C. R.; CANFIELD, R. B. Perineal hernia. In: SLATTER, D. Textbook of smal animal surgery. 3. ed. Philadelphia: Saunders, 2003. cap. 34, p. 487-498.

BILBREY, S. A.; SMEAK, D. D.; DEHOFF, W. Fixation of the deferent ductus for retrodisplacement of the urinary bladder and prostate in canine perineal hernia. Veterinary Surgery, Philadelphia, v. 19, n. 1, p. 24-27, Jan.-Feb. 1990.

BONGARTZ, A. et al. Use of autogenous fascia lata graft for perineal herniorrhaphy in dogs. Veterinary Surgery, Philadelphia, v. 34, n. 4, p. 405-503, July-Aug. 2005.

BRISSOT, H. N.; DUPRE, G. P.; BOUVY, B. M. Use of laparotomy in a staged approach for resolution of bilateral or complicated perineal hernia in 41 dogs. Veterinary Surgery Philadelphia, v. 33, n. 4, p. 412-421, July-Aug. 2004

BURROWS, C. F.; HARVEY, C. E. Perineal hernia in the dog. Journal of Small Animal Practice, Oxford, v. 14, n. 6, p. 315-322, June 1973

CARDOSO, C. G. et al. Utilização de pericádio bovino na herniorrafia perineal em cães - relato de dois casos. In: ENCONTRO INTERNACIONAL DE PRODUÇÃO CIENTÍFICA CESUMAR 7., 2011, Maringá. Anais... Maringá: CESUMAR - Centro Universitário de Maringá, 2011.

CHAMBERS, J. N.; RAWLINGS, C. A. Applications of a semitendinosus muscle flap in two dogs. Journal of the American Veterinary Medical Association, Ithaca, v. 199, n. 1, p. 84-86, July 1991.

CLARKE, R. E. Perineal herniorrhaphy in the dog using polypropylene mesh. Australian Veterinary Practitioner, Hurstville, New South Wales, v. 19, n. 1, p. 8-14, 1989.

DALECK, C. R. et al. Reparação da hérnia perineal em cães com peritônio de bovino conservado em glicerina. Ciência Rural, Santa Maria, v. 22, n. 2, p. 179-183, maio/ago. 1992.

D'ASSIS, M. J. M. H. et al. Colopexia e deferentopexia associadas à omentopexia no tratamento da hérnia perineal em cães: um estudo de trinta casos. Ciência Rural, Santa Maria, v. 40, n. 2, p. 341-347, fev. 2010

DIETERICH, H. F. Symposium on surgical techniques in small animal practice. Perineal hernia repair in the canine. Veterinary Clinics of North America Small Animal Practice, Philadelphia, v. 5, n. 3, p. 383-399, Aug. 1975.

DÓREA, H. C.; SELMI, A. L.; DALECK, C. R. Herniorrafia perineal em cães - estudo retrospectivo de 55 casos. Ars Veterinaria, Jaboticabal, v. 18, n. 1, p. 20-24, 2002.

DORN, A. S.; CARTEE, R. E.; RICHARDSON, D. C. A preliminary comparison of perineal hernia in the dog and man. Journal of the American Animal Hospital Association, Lakewood CO, v. 18, n. 4 , p. $624-632,1982$

EARLEY, D. T.; KOLATA, R. J. Perineal hernia in the dog: na alternative method of Corretion. In: BOJRAB, M. J. Current techniques in small animal surgery. Philadelphia: Lea \& Febiger, 1983. cap. 30 , p. $405-407$

FERREIRA, F.; DELGADO, E. Hérnias perineais nos pequenos animais. Revista Portuguesa de Ciências Veterinárias, Lisboa, v. 98, n. 545, p. 3-9, jan./mar. 2003.

FRANKLAND, A. L. Use of porcine dermal collagen in the repair of perineal hernia in dogs - a preliminary report. Veterinary Record, London, v. 119, n. 1, p. 13-14, July 1986.

GOBBETTI, $M$. Tension band herniorrhaphy in canine perineal hernia: evaluation of the role of colopexy on surgical and clinical outcome. 2012. 55 f. Tese (Doutorado) - Università degl Studi di Milano, Milano, 2012.

GRAND, J. G.; BUREAU, S.; MONNET, E. Effects of urinary bladder retroflexion and surgical technique on postoperative complication rates and long-term outcome in dogs with perinea hernia: 41 cases (2002-2009). Journal of the American Veterinary Medical Association, Ithaca, v. 243, n. 10, p. 1442-1447, Nov. 2013

HARDIE, E. M.; KOLATA, R. J.; EARLEY, T. D. Evaluation of internal obturator muscle transposition in treatment of perineal hernia in dogs. Veterinary Surgery, Philadelphia, v. 12, n. 2, p. 69-72, Apr. 1983

HARVEY, C. E. Treatment of perineal hernia in the dog - a reassessment. Journal of Small Animal Practice, Oxford, v. 18, n. 8, p. 505-511, Aug. 1977.

HAYES JUNIOR, H. M.; WILSON, G. P.; TARONE, R. E. The epidemiologic features of perineal hernia in 771 dogs. Journal American Animal Hospital Association, Lakewood, CO, v. 14, n. 6 , p. 703-707, 1978.

HOLMES, J. R. Perineal hernia in dog. The Veterinary Record, London, v. 76, n. 44, p. 1250$-1251,1964$.

HOSGOOD, G. et al. Perineal herniorrhaphy: perioperative data from 100 dogs. Journal of the American Animal Hospital Association, Lakewood, CO, v. 31, n. 4, p. 331-342, 1995.

KRAHWINKEL, D. J. Rectal Diseases and Their Role in Perineal Hernia. Veterinary Surgery, Philadelphia, v. 12, n. 3, p. 160-165, July 1983.

LARSEN, J. S. Perineal herniorrhaphy in dogs. Journal of the American Veterinary Medical Association, Ithaca, v. 149, n. 3, p. 277-280, Aug. 1966.

LEAL, L. M. et al. Herniorrafia perineal com tela de polipropileno em cão - relato de caso. Revista Científica Eletrônica de Medicina Veterinária, Garça, SP, v. 9, n. 18, jan. 2012.
MANN, F. A. et al. Androgen receptors in the pelvic diaphragm muscles of dogs with and without perineal hernia. American Journal of Veterinary Research, Chicago, v. 56, n. 1, p. 134-139, Jan. 1995.

MATERA, A. et al. Hérnia perineal no cão-tratamento cirúrgico mediante utilização de malha de polipropileno. Brazilian Journal of Veterinary Research and Animal Science, São Paulo, v. 18, n. 1, p. 37-41, 1981.

MATTHIESEN, D. T. Diagnosis and management of complications occurring after perineal herniorraphy in dogs. Compendium on Continuing Education for the Practice Veterinary, Trenton, NJ, v. 11, n. 7, p. 797-803, 1989.

MERCHAV, R. et al. Expression of relaxin receptor LRG7, canine relaxin, and relaxin-like factor in the pelvic diaphragm musculature of dogs with and without perineal hernia. Veterinary Surgery, Philadelphia, v. 34, n. 5, p. 476-481, set./out. 2005.

MORELLO, E. et al. Modified semitendinosus muscle transposition to repair ventral perineal hernia in 14 dogs. Journal of Small Animal Practice, Oxford, v. 56, n. 6, p. 370-376, June 2015 MORTARI, A. C.; RAHAL, S. C. Hérnia perineal em cães. Ciência Rural, Santa Maria, v. 35 , n. 5, p. 1220-1228, set.-out. 2005.

MORTARI, A. C. et al. Electromyographical, ultrasonographical and morphological modifications in semitendinous muscle after transposition as ventral perineal muscle flap. Journal of Veterinary Medicine Series A: physiology pathology clinical medicine, Berlin, v. 52, n. 7, p. 359-365, Sept. 2005.

OLIVEIRA, R. V. P. et al. Transposição do músculo semitendinoso no tratamento da hérnia perineal em cães. Enciclopédia Biosfera, Goiânia, v. 10, n. 19, p. 1769-1778, 2014.

ORSHER, R. J.; JOHNSTON, D. E. The surgical treatment of perineal hernia in dogs by transposition of the obturador muscle. Compendium of Continuing Education for the Practicing Veterinarian, Trenton, NJ, v. 7, n. 3, p. 233-239, 1985.

PEKCAN, Z. et al. Clinical and Surgical Evaluation of Perineal Hernia in Dogs: 41 Cases. Kafkas Universitesi Veteriner Fakultesi Dergisi, v. 16, n. 4, p. 573-578, 2010.

PETTIT, G. D. Perineal hernia in the dog. Cornell Veterinary, Ithaca, v. 52, p. 261-279, Apr. 1962. PRATUMMINTRA, K. et al. Perineal hernia repair using an autologous tunica vaginalis communis in nine intact male dogs. Journal of Veterinary Medical Science, Tokio, v. 75, n. 3, p. 337-341, 2012

RADLINSKY, M. G. Surgery of the Digestive System. In: FOSSUM, T. W. Small animal surgery. 4. ed. Missouri: Elsevier Mosby, 2013. cap. 20, p. 568-573.

RAFFAN, P. J. A new surgical technique for repair of perineal hernia in the dog. Journal of Small Animal Practice, Oxford, v. 34, n. 1, p. 13-19, Jan. 1993.

RAISER, A. G. Herniorrafia perineal em cães - análise de 35 casos. Brazilian Journal Veterinary Research Animal Science, São Paulo, v. 31, n. 3/4, p. 252-260, 1994.

ROBERTSON, J. J. Perineal hernia repair in dogs. Modern Veterinary Practice, Wheaton, III, v. 65, n. 5, p. 365-368, May 1984

SPICCIATI, W. Contribuição para o estudo do tratamento cirúrgico da hérnia perineal com prostatectomia no cão. Revista da Faculdade de Medicina Veterinária, São Paulo, v. 8, n. 3, p. $771-806,1971$

SPREULL, J. S.; FRANKLAND, A. L. Transplanting the superficial gluteal muscle in the treatment of perineal hernia and flexure of the rectum in the dog. The Journal of Small Animal Practice, Oxford, v. 21, n. 5, p. 265-278, May 1980.

STOLL, M. R. et al. The use of porcine small intestinal submucosa as a biomaterial for perineal herniorrhaphy in the dog. Veterinary Surgery, Philadelphia, v. 31, n. 4, p. 379-390, July-Aug. 2002.

SZABO, S.; WILKENS, B.; RADASCH, R. M. Use of Polypropylene Mesh in Addition to Internal Obturator Transposition: A Review of 59 Cases (2000-2004). Journal of the American Animal Hospital Association, Lakewood, CO, v. 43, n. 3, p. 136-142, 2007.

VNUK, D. et al. A modified salvage technique in surgical repair of perineal hernia in dogs using polypropylene mesh. Veterinarni Medicina, v. 51, n. 3, p. 111-117, Mar. 2006.

WEAVER, A. D.; OMAMEGBE, J. O. Surgical treatment of perineal hernia in the dog. Journal of Small Animal Practice, Oxford, v. 22, n. 12, p. 749-758, Dec. 1981.

ZERWES, M. B. C. et al. Avaliação do tratamento cirúrgico da hérnia perineal em cães com o reforço de membrana de pericárdio equino preservado em glicerina a $98 \%$. Brazilian Journal of Veterinary Research and Animal Science, São Paulo, v. 48, n. 3, p. 220-227, 2011. 